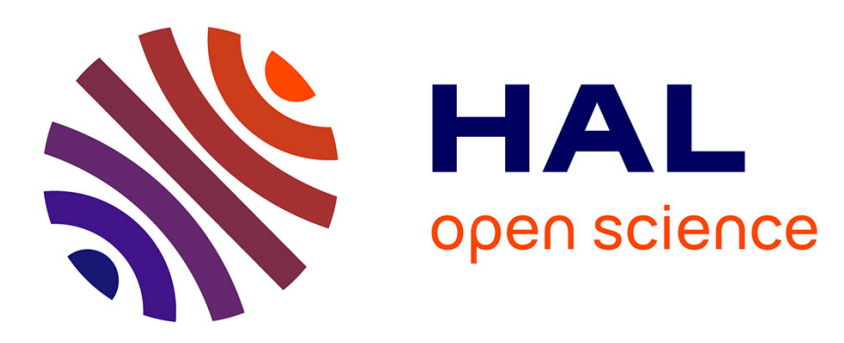

\title{
Atrial Fibrillation in a Dual-Chamber ICD Recipient with Activation of the Ventricular Intrinsic Preference Algorithm: What Is the Mechanism?
}

R.P. Martins, V. Galand, N. Behar, P. Mabo, J.-C. Daubert, Christophe Leclercq

\section{To cite this version:}

R.P. Martins, V. Galand, N. Behar, P. Mabo, J.-C. Daubert, et al.. Atrial Fibrillation in a DualChamber ICD Recipient with Activation of the Ventricular Intrinsic Preference Algorithm: What Is the Mechanism?. PACE - Pacing and Clinical Electrophysiology, 2016, 39 (8), pp.880-882. 10.1111/pace.12900 . hal-01372362

HAL Id: hal-01372362

https://hal-univ-rennes1.archives-ouvertes.fr/hal-01372362

Submitted on 13 Oct 2016

HAL is a multi-disciplinary open access archive for the deposit and dissemination of scientific research documents, whether they are published or not. The documents may come from teaching and research institutions in France or abroad, or from public or private research centers.
L'archive ouverte pluridisciplinaire HAL, est destinée au dépôt et à la diffusion de documents scientifiques de niveau recherche, publiés ou non, émanant des établissements d'enseignement et de recherche français ou étrangers, des laboratoires publics ou privés. 


\title{
Atrial fibrillation in a dual chamber ICD recipient with activation of the ventricular intrinsic preference algorithm: what is the mechanism?
}

\author{
Raphael P. Martins, M.D., Ph.D. ${ }^{1,2,3}$, Vincent Galand, M.D. ${ }^{1,2,3}$, Nathalie Behar, M.D. ${ }^{1,2,3}$, \\ Philippe Mabo, M.D, Ph.D. ${ }^{1,2,3}$, Jean-Claude Daubert, M.D. ${ }^{1,2,3}$, Christophe Leclercq, M.D., \\ Ph.D. ${ }^{1,2,3}$
}

\section{Working group address:}

1 CHU Rennes, Service de Cardiologie et Maladies Vasculaires, Rennes, F-35000, France

2 Université de Rennes 1, LTSI, Rennes, F-35000, France

3 INSERM, U1099, Rennes, F-35000, France

\section{Corresponding author:}

Raphael P. Martins, Service de Cardiologie et Maladies Vasculaires, CHU de Rennes, 2 rue Henri Le Guilloux, 35000 Rennes, France. Tel: + 33299282 507, Fax: +33 299282529 , email: raphael.martins@chu-rennes.fr

\section{Word count: 1161}

Type: Pacemaker/ICD problem

Conflicts of interests: None. 


\section{Case presentation}

A 72-year-old man with ischemic cardiomyopathy and sinus node dysfunction was implanted with a dual chamber implantable cardioverter defibrillator (ICD) (St Jude Medical Ellipse DR 2277-36, St. Paul, MN, USA) for secondary prevention. The programmed parameters were as follows: DDDR 50-130 bpm, paced atrioventricular (AV) delay $(\mathrm{AVD})=150 \mathrm{~ms}$, atrial pacing threshold $=1 \mathrm{~V}$, atrial detection $=2.5 \mathrm{mV}$, ventricular pacing threshold $=0.75 \mathrm{~V}$, ventricular detection $=12 \mathrm{mV}$, post-ventricular atrial refractory period $($ PVARP $)=275 \mathrm{~ms}$. The "Ventricular Intrinsic Preference" (VIP) mode was programmed with the following settings, VIP extension: 200ms, search interval: 30sec, search cycles: 3 beats. Ten months after implantation, patient was asymptomatic. Atrial and ventricular pacing burdens were $73 \%$ and $<1 \%$, respectively. No VT episodes occurred during follow-up, but device interrogation revealed 24 episodes of atrial fibrillation (AF), as shown in Figure 1. What is the mechanism of AF initiation? How could you reprogram the device to avoid these AF episodes?

\section{Commentary}

Many studies demonstrated that right ventricular (RV) pacing can induce dyssynchronous left ventricular contraction and precipitate left ventricular dysfunction, resulting in adverse outcomes such as AF or heart failure.[1] Few strategies can reduce RV pacing burden in dual chamber systems, i.e. programming DDD pacing with a fixed long AV delay, AV hysteresis or specific AAI-DDD mode switch algorithms.

All device brands developed their own mode switch algorithm, most of them based on an AAI pacing mode while monitoring AV conduction. The pacemaker switches to DDD pacing mode in case of persistent loss of $\mathrm{AV}$ conduction, while returning to AAI mode if $\mathrm{AV}$ 
conduction resumes. One of the major drawbacks of such algorithms is that long AV delays are permitted, leading to AV dyssynchrony, diastolic mitral regurgitation, or benign arrhythmias such as AV nodal reentrant tachycardia as previously described.[2] Nonconducted atrial sensing/pacing events may also occur without mode switching to DDD mode, resulting in short-long-short ventricular sequences. Such short-long-short cycles have been described to infrequently trigger malignant ventricular arrhythmias in patients with cardiomyopathies. [3-4]

The VIP algorithm functioning is different since non-conducted atrial events are not tolerated permitted and the algorithm works like a periodic AV-delay hysteresis. Consequently, every single atrial event will be followed by a ventricular sensed or paced beat and short-long-short ventricular cycles cannot happen. Three parameters have to be programmed, namely the "VIP extension", the "search interval" and the "search cycles". Periodically ("search interval", from $30 \mathrm{sec}$ to $30 \mathrm{~min}$ ), the device extends the programmed AV interval by the "VIP extension" (from 50 to $200 \mathrm{~ms}$ ) for a determined number of beats ("search cycles", 1, 2 or 3 consecutive beats). When an intrinsic $\mathrm{R}$ wave is sensed by the device within the AV delay + VIP extension, spontaneous ventricular activations occurs and the device functions as a single chamber atrial pacemaker. When no intrinsic $\mathrm{R}$ wave is sensed within the AV delay + VIP extension, the AV delay shortens after the programmed "search cycles" to its original programmed value. Consequently, the device is designed to sustain long AV delays, which may favor retrograde VA conduction and initiate a pacemaker-mediated tachycardia (PMT), as previously described. [5]

Initially, as shown in figure 2 , the atrium is paced since the rate response mode is activated $(\mathrm{SIR}=$ Sensor indicated rate), with intrinsic ventricular activation occurring after a long AV delay (mark 1, Figure 2). The third ventricular beat is paced since no intrinsic $\mathrm{R}$ wave was detected within the AV delay + VIP extension (mark 2, Figure 2). One can appreciate that 
after this paced beat, a retrograde atrial conduction occurs, detected by the device but not taken into account, since it occurs in the PVARP. An AV delay is not triggered after this atrial event and the device continues to inadvertently and ineffectively pace the atrium. After the third "VP" with long AV delay (= programmed AV delay + VIP extension), the AV delay returns to its original programmed value (i.e. $150 \mathrm{~ms}$, mark 3, Figure 2), still responsible for a clear retrograde atrial conduction (mark 4, Figure 2). At this time, a "pseudo-PMT" is triggered, the ventricular pacing favoring retrograde VA conduction, which constantly occurs during the PVARP, and the device continues to inadvertently and ineffectively pace the atrium (since the atrial pacing spike occurs during the absolute refractory period of the atrium) which perpetuate the phenomenon. Progressively, the atrial pacing rate slowly decreases (up to $707 \mathrm{~ms}$ ), and at one given time (mark 5, figure 2), the atrial pacing spike captures the atria, probably during the vulnerable window, which consequently triggers AF (mark 6, Figure 2), activating the device mode switching (“CAM”).

In our case, we describe for the first time the occurrence of episodes of AF initiated by the VIP algorithm activation. Long AV delay favored retrograde VA conduction, initially occurring during the PVARP, and not triggering an AV delay. Consequently, the device continued to inadvertently pace the atrium without capturing it, the atrium being in absolute refractory period. Once the pacing spike occurred in the vulnerable window of the refractory period and captured the atrium, an episode of AF occurred. In our patient, reprogramming a shorter VIP extension was sufficient to avoid retrograde VA conduction, while maintaining spontaneous ventricular activation without significant increase in ventricular pacing burden. One may assume that shortening the PVARP could have avoided AF episodes, since the phenomenon would have generated a PMT, detected and stopped by the device after the ninth “AS-VP” at maximal tracking rate. 
To note, if one looks closely at the ventricular EGMs during the "pseudo-PMT", there is variation in the "Vp" complexes morphology: VP\#4 and Vp\#12 and Vp\#13 (first two complexes of the bottom strip of Figure 1) appear to be fully paced while Vp\#5-11 appear to be different and may represent varying levels of fusion. Therefore, it cannot be excluded that this may represent a form of atrio-ventricular nodal reentrant tachycardia (AVNRT, slow-fast or slow-intermediate) that would have persisted even in the absence of ventricular pacing. However, spontaneous AVNRT had never been observed in this patient, and this hypothesis, although theoretically possible, is unlikely.

In summary, we describe here a new pro-arrhythmic effect of the VIP algorithm, generating $\mathrm{AF}$ in a patient with no history of atrial arrhythmias. Clinicians should be aware of such potential events, since the reprogramming of the device may prevent new episodes and avoid the initiation of otherwise unnecessary anticoagulation.

\section{References}

1. Tops LF1, Schalij MJ, Bax JJ. The effects of right ventricular apical pacing on ventricular function and dyssynchrony implications for therapy. J Am Coll Cardiol. 2009;54:764-76.

2. Frisch DR1, Kenia AS, Walinsky P, Balog J. Managed ventricular pacing facilitating atrioventricular nodal reentrant tachycardia. Pacing Clin Electrophysiol. 2014;37:156871

3. Vavasis C1, Slotwiner DJ, Goldner BG, Cheung JW. Frequent recurrent polymorphic ventricular tachycardia during sleep due to managed ventricular pacing. Pacing Clin Electrophysiol. 2010;33:641-4.

4. Mansour F1, Khairy P. Electrical storm due to managed ventricular pacing. Heart Rhythm. 2012;9:842-3.

5.Barold SS1, Stroobandt RX. Pacemaker-mediated tachycardia initiated by an atrioventricular search algorithm to minimize right ventricular pacing. J Electrocardiol. 2012;45:336-9. 


\section{Figure legends:}

Figure 1: Initiation of an AF episode. From top to bottom: atrial EGM, ventricular EGM, markers and delays (AA, VV, and AV delays, respectively).

Ap: Atrial pacing; As: Atrial sensing; CAM: Automatic mode switching; EGM: Electrograms; SIR: Sensor indicated rate; VIP: ventricular intrinsic preference; Vp: ventricular pacing; Vs: Ventricular sensing

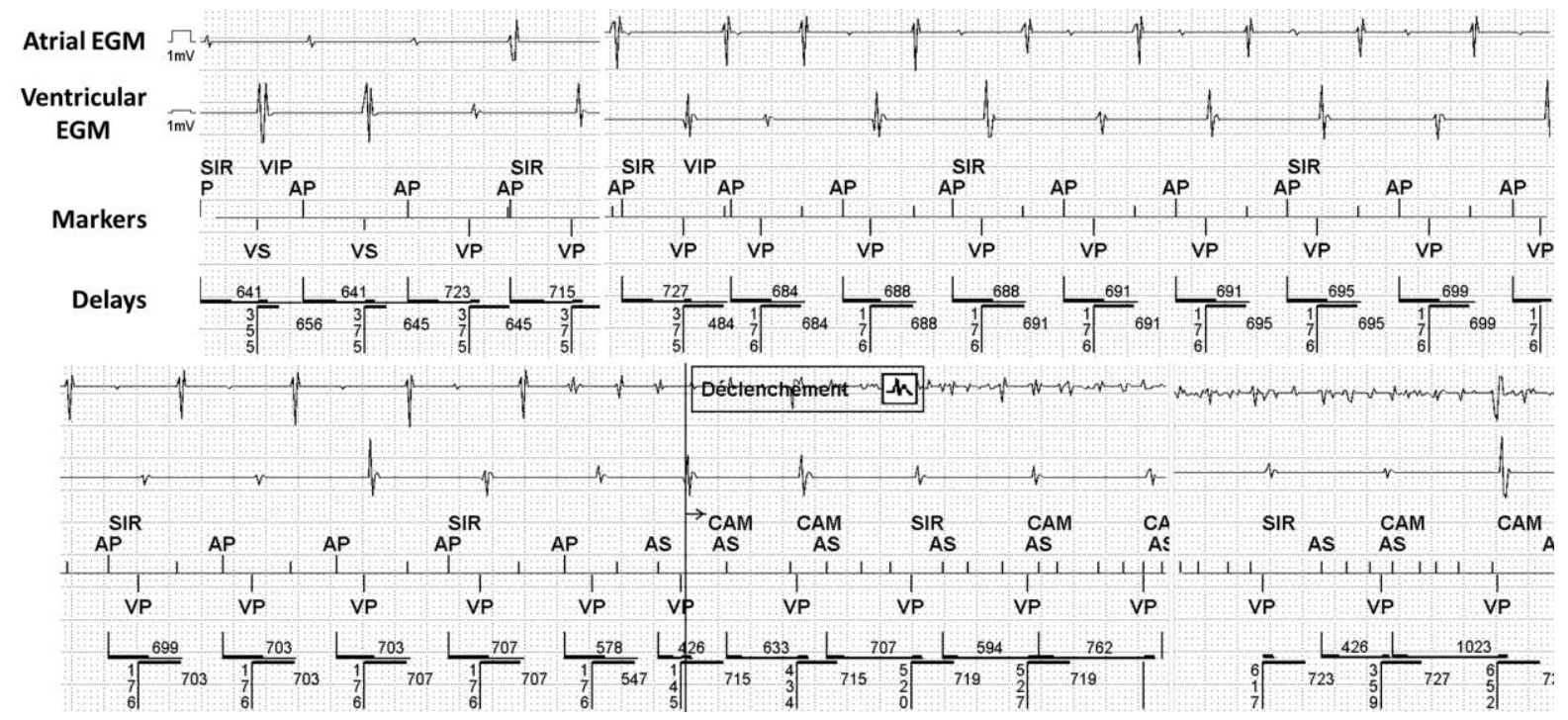


Figure 2: See text for details.

\section{(1) (2) (3)(4)}
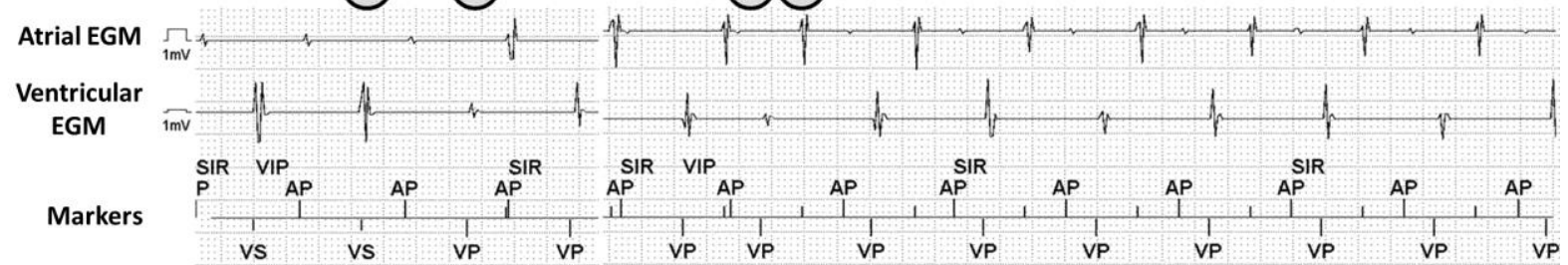

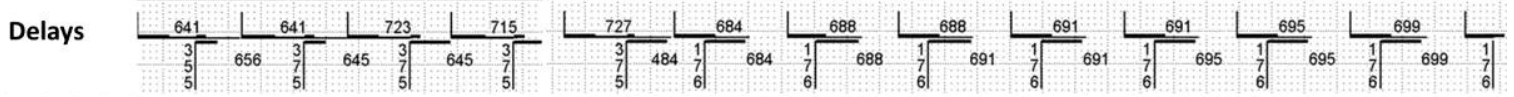

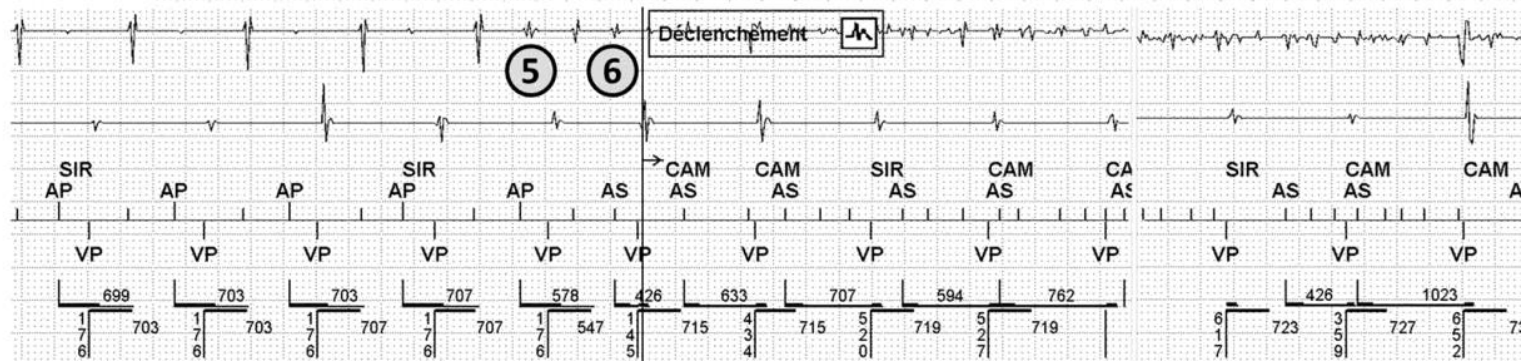

(1) 